\title{
Effect of Specimen Thickness on the Aging of Al-Zn Alloys
}

\author{
By Mutsuo Ohta*, Masuo Yamada*, Teruto Kanadani** \\ and Akira Sakakibara*
}

\begin{abstract}
Effect of the specimen thickness on the aging of Al-4 and 10 mass\% Zn alloys was studied by measuring the electrical resistance and the intensity of small-angle X-ray scattering (SAXS). When the quenching temperature $\left(T_{\mathrm{Q}}\right)$ was high, the value of resistance attained at the stage of aging where the change in resistivity ceased virtually was not influenced by the specimen thickness. In the case of low $T_{\mathrm{Q}}$, the resistance was higher for the thin specimen because of the impoverishment of vacancies. The total amount of GP zones formed decreased with decreasing thickness or $T_{\mathrm{Q}}$ in the case of low $T_{\mathrm{Q}}$, but did not depend upon the thickness or $T_{\mathrm{Q}}$ in the case of high $T_{\mathrm{Q}}$. Both the Guinier radius and the Porod radius for the specimen of $0.1 \mathrm{~mm}$ thickness were smaller than those for the $0.2 \mathrm{~mm}$ thick one when $T_{\mathrm{Q}}$ was low, but they became independent of thickness when $T_{\mathrm{Q}}$ was high. The quenching temperature at which the Guinier radius was maximum, was higher for the $0.1 \mathrm{~mm}$ thick specimen than that for the $0.2 \mathrm{~mm}$ thick one. These results are discussed from the viewpoint of the diffusion of vacancies to the surface and their annihilation during aging.
\end{abstract}

(Received March 16, 1987)

Keywords: aging, aluminum-zinc alloy, small-angle X-ray scattering, integrated intensity, Guinier radius, Porod radius, vacancy diffusion, surface, electrical resistance

\section{Introduction}

Many experiments have been conducted on the aging of $\mathrm{Al}-\mathrm{Zn}$ alloys using various methods and dimensions of specimens. For instance, the thickness of specimens when heat-treated is about $0.1 \mathrm{~mm}$ for electron microscopy or small-angle X-ray scattering (SAXS), and more than $1 \mathrm{~mm}$ for hardness testing.

The present authors ${ }^{(1)}$ previously used the hardness test to study the age hardening of the $\mathrm{Al}-12$ mass $\% \mathrm{Zn}$ alloy aged at room temperature. They found that the Vickers hardness number depended on the location of indentation in the grain of the specimen aged after quenching from a low temperature. The hardness number near the grain boundary (within $50 \mu \mathrm{m}$ of boundary) and within $50 \mu \mathrm{m}$ of the

* This paper was originally published in Japanese in $\mathrm{J}$. Japan Inst. Metals, 50 (1986), 887.

** School of Engineering, Okayama University, Okayama 700, Japan.

*** Faculty of Engineering, Okayama University of Science, Okayama 700, Japan surface was slightly smaller than that of the interior of the grain. Small spherical GP zones were observed, by using an electron microscope, in the thin foil made from the region near the surface of the aged specimen of 1 $\mathrm{mm}$ thickness, while there were ellipsoidal, a little larger zones in the foil made from the interior region. These findings have been interpreted as signifying the suppression of the growth of GP zones in the regions near the grain boundaries and the regions near the specimen surface, due to a decrease in the vacancies induced by effective annihilation at the grain surface as well as at the internal sinks, such as dislocations.

According to the above interpretation, it may be expected that the process of aging, total amount of GP zones formed, etc. are more or less different between the specimens of less than $0.1 \mathrm{~mm}$ thickness and those of more than $0.2 \mathrm{~mm}$ thickness. Thus the thickness of the specimen is considered to be one important factor for understanding the process of aging. In this article, the effect of thickness on the aging of $\mathrm{Al}-4 \mathrm{mass} \% \mathrm{Zn}$ and $\mathrm{Al}-10$ mass $\% \mathrm{Zn}$ alloys is investigated by means of resistometry and 
the measurement of SAXS intensities.

\section{Experimental Procedures}

It has been reported ${ }^{(2)(3)}$ that the values of resistivity obtained at the stage of aging where the change of resistivity ceased substantially $\left(\rho_{\mathrm{E}}\right)$ was different every time heat treatment was carried out even when the same specimen was quenched and aged under identical conditions. This scattering of $\rho_{\mathrm{E}}$ is closely related to the scattering of the as-quenched resistivity $\left(\rho_{0}\right)$. Therefore, in the present study, the SAXS experiment was carried out with those specimens which showed average behavior in resistance change during aging.

\section{Specimen}

$\mathrm{Al}-4$ mass $\% \mathrm{Zn}$ and $\mathrm{Al}-10$ mass\% $\mathrm{Zn}$ alloys (nominal composition) were prepared from 99.996\% pure aluminum and $99.999 \%$ pure zinc. They were melted in the high alumina crucible in the air. Ingots, $15 \mathrm{~mm}$ in diameter and about $150 \mathrm{~mm}$ in length, were homogenized at $723 \mathrm{~K}$ for $180 \mathrm{ks}$. After peeling, they were hot-forged repeatedly at around $723 \mathrm{~K}$ to plates of $5 \mathrm{~mm}$ thickness. The plates were coldrolled several times with appropriate intermediate annealing at $723 \mathrm{~K}$, thus making strips with various thicknesses of $0.1 \mathrm{~mm}, 0.2$ $\mathrm{mm}, 0.4 \mathrm{~mm}$ and $0.6 \mathrm{~mm}$. From these strips, specimens were made for resistometry and $\mathrm{X}$ ray measurement, which were $7 \mathrm{~mm}$ wide and about $30 \mathrm{~mm}$ long and had leads on both ends. For the X-ray measurement, specimens 0.1 $\mathrm{mm}$ or $0.2 \mathrm{~mm}$ thick were used. Resistometry and the measurement of SAXS intensity were made on the same specimens.

The method of heat treatment was the same as described previously ${ }^{(3)}$. It has been reported $^{(4)}$ that dezincification did not occur when Al-Zn alloys were heat-treated in the air. Systematic variation was not found in the asquenched resistivities and in the aging curves when a specimen was heat-treated more than thirty times repeatedly ${ }^{(3)}$. Moreover, as described later, the integrated intensity of SAXS from a specimen aged thoroughly did not vary with repeated heat treatments.

\section{Measurement of electrical resistance}

Electrical resistance was measured at $77 \mathrm{~K}$, calibrated using a dummy specimen, by the usual potentiometric method with the Yokogawa resistometry system (Type 3802-64). Values of four significant figures were obtained by this method. Resistances of different specimens were normalized by dividing by the resistance of each specimen, $R_{473}$, which was obtained after quenching from $473 \mathrm{~K}$.

\section{Measurement of SAXS intensities}

SAXS intensities were measured photographically using a point-focusing $\mathrm{CuK} \alpha$ radiation. This was done by reflection using a purealuminum monochromator ${ }^{(5)(6)}$. The specimen was cooled at about $120 \mathrm{~K}$ during the exposure. The total dose of the incident beam was calibrated by measuring the intensity scattered by the air in the path during each exposure time. To suppress the error due to the granular structure of the film, the density at a given $s$ value was obtained by averaging the densities in the appropriate region around the $s$ value measured at an interval of $0.002 \mathrm{~nm}^{-1}$ of $s$, where $s=2 \sin \theta / \lambda$. Scattered intensities were measured in the region $0.08 \mathrm{~nm}^{-1}<s<2.24$ $\mathrm{nm}^{-1}$, that is, $0.7^{\circ}<2 \theta<20^{\circ}$ in scattering angle.

Calibration for the specimen thickness is important in the present study because the scattered intensities of specimens with a largely different thickness must be compared. Mass absorption coefficients of aluminum and zinc for $\mathrm{CuK} \alpha$ radiation, 4.76 and $5.65 \mathrm{~m}^{2} / \mathrm{kg}$ respectively, were determined experimentally and used in the following calculations. These values are smaller than those found in the International Tables $^{(7)}$ by about $5 \%$ and close to those calculated for $\mathrm{CuK} \alpha^{(8)}$.

Scattered intensity, $i(s)$, calibrated for the apparatus and for the angular dependence of the atomic scattering factor, consists not only of small-angle scattering from the GP zones, $i_{\mathrm{GP}}(s)$, but of Compton scattering, $i_{\mathrm{C}}(s)$, temperature scattering, $i_{\mathrm{T}}(s)$, and Laue scattering from the matrix and GP zones, $i_{\mathrm{L}, \mathrm{m}}(s)$ and $i_{\mathrm{L}, \mathrm{GP}}(s)$. In the angular region of the present measurement, the intensities of Compton scat- 


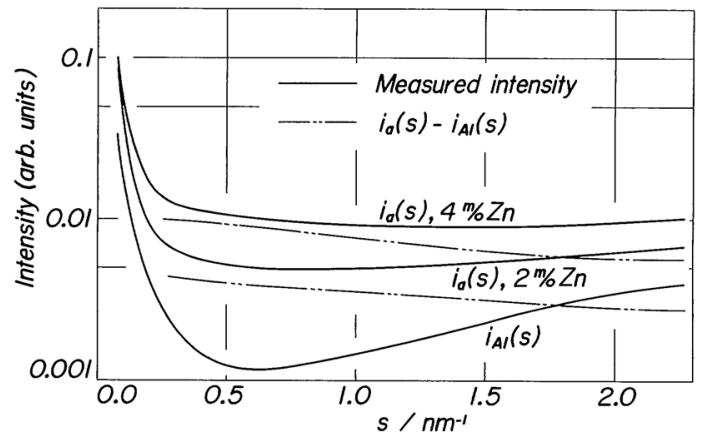

Fig. 1 Measured scattering intensities from $4 \%$ alloy, $2 \%$ alloy and pure $\mathrm{Al}$ (solid lines) and Laue scattering intensities of the alloys calculated from them (chained lines).

tering from aluminum and zinc are nearly equal $^{(9)(10)}$. In Fig. 1 are shown the scattering intensity curves, $i_{\mathrm{a}}(s)$, from solid solutions of 2 mass $\% \mathrm{Zn}$ and 4 mass $\% \mathrm{Zn}$ which correspond to the quasi-equilibrium solubility for GP zones at $263 \mathrm{~K}$ and $293 \mathrm{~K}$ respectively ${ }^{(11)}$, and the scattering intensity curve from pure aluminum, $i_{\mathrm{Al}}(s)$. Laue scattering from those solid solutions, $i_{\mathrm{L}, \mathrm{a}}(s)=i_{\mathrm{a}}(s)-i_{\mathrm{Al}}(s)$, decreases monotonically with $s$. The intensity $i_{\mathrm{L}, \mathrm{m}}(s)$ is considered to be nearly equal to $i_{\mathrm{L}, \mathrm{a}}(s)$. Therefore, $i_{\mathrm{a}}(s)$ is nearly equal to the sum of four kinds of intensities, that is, $i_{\mathrm{C}}(s), i_{\mathrm{T}}(s), i_{\mathrm{L}, \mathrm{m}}(s)$ and the intensity which may be regarded as a small-angle scattering from the specimen surface ${ }^{(12)}$ and significant in the region $s<0.2 \mathrm{~nm}^{-1}$. Thus it may be $i(s)-i_{\mathrm{a}}(s)=i_{\mathrm{GP}}(s)+i_{\mathrm{L}, \mathrm{GP}}(s)$. The intensity $i_{\mathrm{L}, \mathrm{GP}}(s)$ is smaller than $i_{\mathrm{L}, \mathrm{m}}(s)$ (for instance, calculated values of $i_{\mathrm{L}, \mathrm{GP}}(s)$ for 4 mass $\% \mathrm{Zn}$ alloy at $263 \mathrm{~K}$ and for 10 mass $\% \mathrm{Zn}$ alloy at $293 \mathrm{~K}$ are about $1 / 4$ and $1 / 2$ of $i_{\mathrm{L}, \mathrm{m}}(s)$, respectively). The value of $i_{\mathrm{L}, \mathrm{GP}}(S)$ is considered to be independent of $s$ and is therefore obtained from the slope of the linear part of $s^{4}$ vs $s^{4}\{i(s)$ $\left.-i_{\mathrm{a}}(s)\right\}$ plot. The plot was almost linear in the range of $0.8 \mathrm{~nm}^{-1}<s<1.4 \mathrm{~nm}^{-1}$ for the present scattering curves. Using the intersection of this straight line with the ordinate, $k$, and assuming that intensities in the range of $s<0.08 \mathrm{~nm}^{-1}$ obey the Guinier approximation, integrated intensity $q_{0}$ and Porod radius $R_{\mathrm{P}}$ are calculated as follows:

$$
q_{0}=4 \pi \int_{0}^{s_{\mathrm{m}}} s^{2} i_{\mathrm{GP}}(s) \mathrm{d} s+4 \pi k / s_{\mathrm{m}}
$$

$$
R_{\mathrm{P}}=\frac{3}{8 \pi^{3}\left(1-v_{\mathrm{f}}\right)} \cdot \frac{q_{0}}{k}
$$

where $s_{\mathrm{m}}$ is an arbitrary value of $s$ in the range where $s^{4}$ plot is linear and $v_{\mathrm{f}}$ is the volume fraction of GP zones.

If the total amount of precipitation, i.e. $q_{0}$, differs in the specimen of the same composition aged at the same temperature, $i_{\mathrm{L}, \mathrm{m}}(s)$ should differ from $i_{\mathrm{L}, \mathrm{a}}(s)$, but the difference is so small that the same $i_{\mathrm{a}}(s)$ was used.

Integrated intensity $q_{0}$ of the $4 \%$ specimens of $0.2 \mathrm{~mm}$ thickness which were fully aged at $263 \mathrm{~K}$ after quenching from $613 \mathrm{~K}$ was measured in the following cases. Maximum errors then obtained were $\pm 4.5 \%$ when the same aged specimen was examined eight times repeatedly, $\pm 6 \%$ when the same piece was heat-treated under the same conditions every time before six examinations, and $\pm 6 \%$ when six different specimens were aged and examined. Error in $R_{\mathrm{P}}$ is considered to be at the same level as that in $q_{0}$.

\section{Results}

In order to study the effect of the thickness, specimens $0.1,0.2,0.4$ and $0.6 \mathrm{~mm}$ in thickness were aged; at $263 \mathrm{~K}$ for the $4 \%$ alloy and at $293 \mathrm{~K}$ for the $10 \%$ alloy, after quenching from various temperatures. Aging curves in resistance ratio are shown in Figs. 2, 3, 4 and 5 . In the case of the $4 \%$ alloy quenched from $613 \mathrm{~K}$, the maximum value of resistance ratio, $R_{\max } / R_{473}$, is lower, the time to attain the maximum is longer, and the value obtained when the resistance virtually stops changing, $R_{\mathrm{E}} /$ $R_{473}$, is higher for the specimen of $0.1 \mathrm{~mm}$ thickness than for the other thicker specimens.

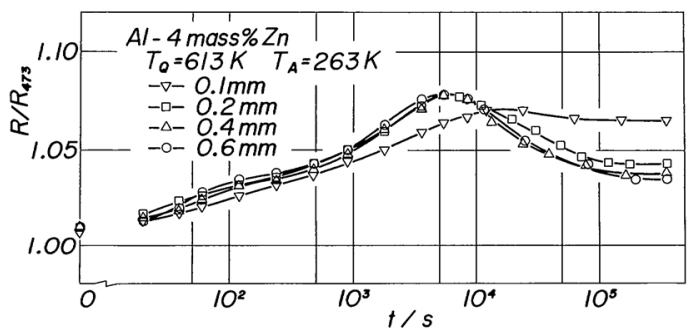

Fig. 2 Variation of isothermal aging curves in resistance with thickness when $4 \%$-alloy specimens were quenched from $613 \mathrm{~K}$ and aged at $263 \mathrm{~K}$. 


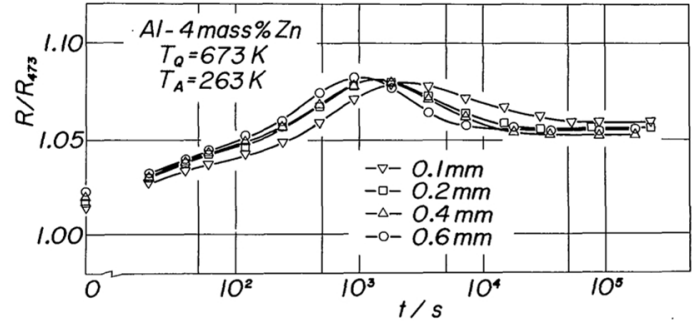

Fig. 3 Variation of isothermal aging curves in resistance with thickness when $4 \%$-alloy specimens were quenched from $673 \mathrm{~K}$ and aged at $263 \mathrm{~K}$.

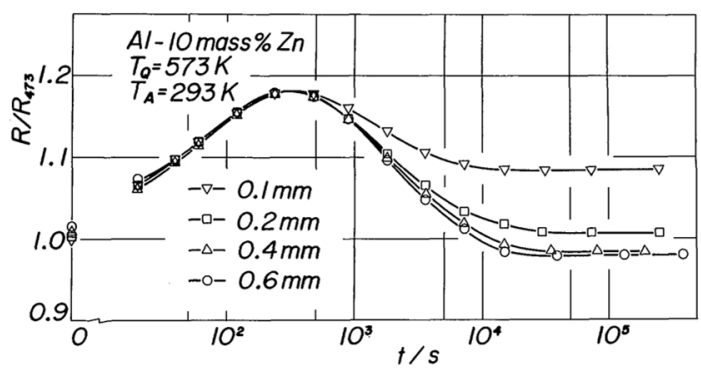

Fig. 4 Variation of isothermal aging curves in resistance with thickness when $10 \%$-alloy specimens were quenched from $573 \mathrm{~K}$ and aged at $293 \mathrm{~K}$.

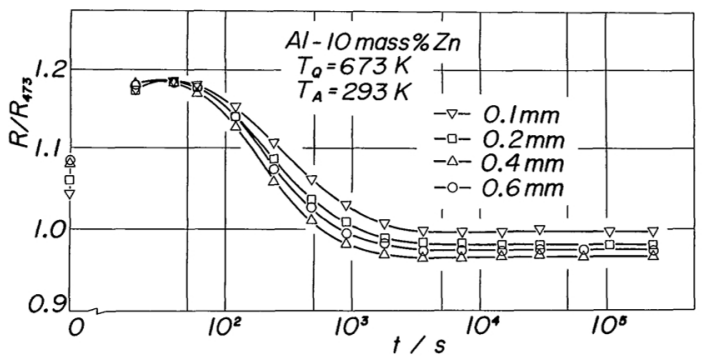

Fig. 5 Variation of isothermal aging curves in resistance with thickness when $10 \%$-alloy specimens were quenched from $673 \mathrm{~K}$ and aged at $293 \mathrm{~K}$.

For the specimens of $0.2 \mathrm{~mm}$ or more in thickness, the aging curves coincide with each other until $R_{\max }$, but $R_{\mathrm{E}} / R_{473}$ decreases with increasing thickness (Fig. 2). With an increasing quenching temperature, the aging curve of the thin specimen becomes similar to the others and the difference in $R_{\mathrm{E}} / R_{473}$ is not observable. (Fig. 3).

In the case of the $10 \%$ alloy quenched from $573 \mathrm{~K}$, the dependence of $R_{\mathrm{E}} / R_{473}$ on the thickness is the same as in Fig. 2, but the aging curves before $R_{\max } / R_{473}$ coincides with each other including the specimen of $0.1 \mathrm{~mm}$ thickness (Fig. 4). At a higher quenching temperature, the effect of the thickness is not observed (Fig. 5).

To investigate the decrease in vacancy concentration during quenching, the variation of resistance in the initial stage of aging was measured for the 4\% alloy quenched from 613 K. In Fig. 6 the initial rate of aging seems to be independent of the thickness.

Figure 7 shows the variation in the integrated intensity of SAXS, $q_{0}$, with quenching temperature, $T_{\mathrm{Q}}$, for the 0.1 and $0.2 \mathrm{~mm}$ thick

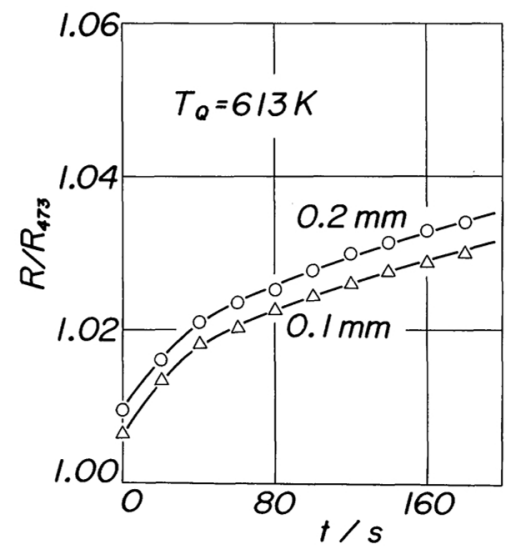

Fig. 6 Initial change in resistance when 4\%-alloy specimens with thickness of $0.1 \mathrm{~mm}$ and $0.2 \mathrm{~mm}$ were aged at $263 \mathrm{~K}$ after quenching from $613 \mathrm{~K}$.

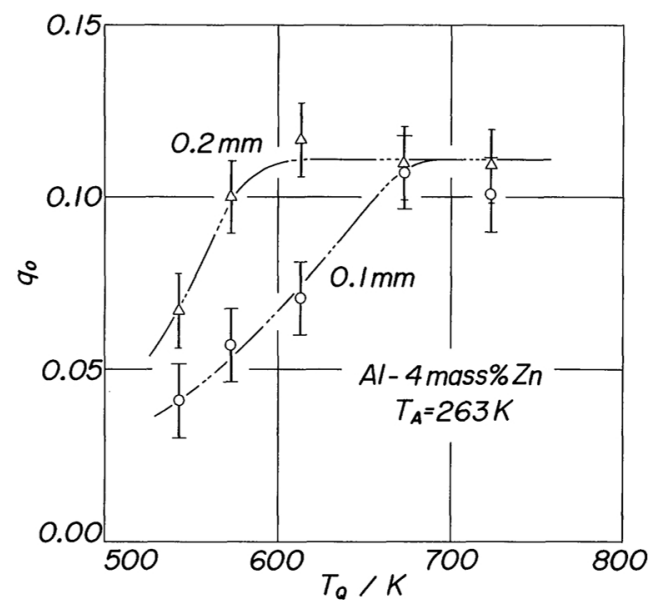

Fig. 7 Variation in $T_{\mathrm{Q}}$-dependence of $q_{0}$ with thickness when $4 \%$-alloy specimens were fully aged at $263 \mathrm{~K}$. 


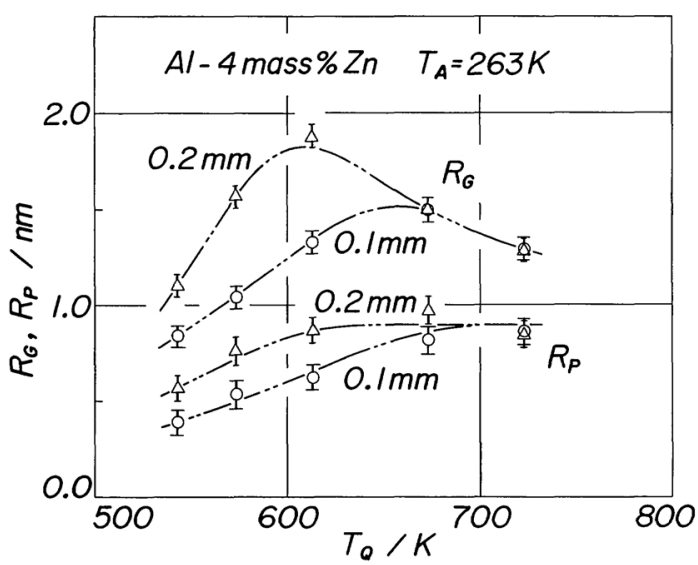

Fig. 8 Variation in $T_{\mathrm{Q}}$-dependence of $R_{\mathrm{C}}$ and $R_{\mathrm{P}}$ with thickness when $4 \%$-alloy specimens were fully aged at $263 \mathrm{~K}$.

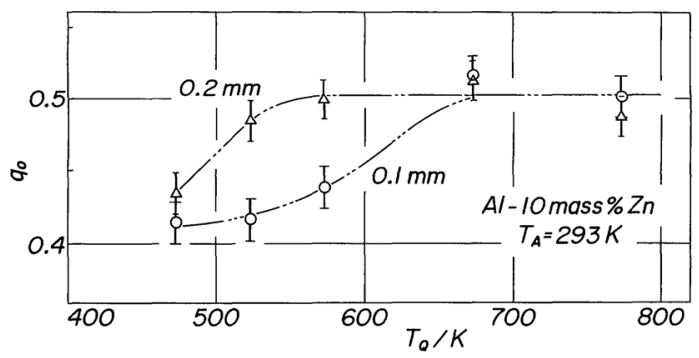

Fig. 9 Variation in $T_{\mathrm{Q}}$-dependence of $q_{0}$ with thickness when $10 \%$-alloy specimens were fully aged at $293 \mathrm{~K}$.

specimens of the $4 \%$ alloy which were fully aged at $263 \mathrm{~K}$ until $R_{\mathrm{E}} / R_{473}$ was attained. A constant value of $q_{0}$ is obtained irrespective of the quenching temperature for both specimens when $T_{\mathrm{Q}}$ is $673 \mathrm{~K}$ or higher. But, when $T_{\mathrm{Q}}$ is $613 \mathrm{~K}$ or lower, $q_{0}$ for the $0.1 \mathrm{~mm}$ specimen decreases with decreasing $T_{\mathrm{Q}}$ and is always smaller than that for the $0.2 \mathrm{~mm}$ specimen beyond the experimental error for $q_{0}$. Even for the $0.2 \mathrm{~mm}$ specimen, $q_{0}$ becomes small when $T_{\mathrm{Q}}$ is as low as $573 \mathrm{~K}$.

Figure 8 shows Guinier radius, $R_{\mathrm{G}}$, and Porod radius, $R_{\mathrm{P}}$, obtained from the intensities of SAXS. Both $R_{\mathrm{G}}$ and $R_{\mathrm{P}}$ for the $0.1 \mathrm{~mm}$ specimen are smaller than those for the $0.2 \mathrm{~mm}$ specimen when $T_{\mathrm{Q}}$ is low, but become independent of specimen thickness when $T_{\mathrm{Q}}$ is higher than or equal to $673 \mathrm{~K}$. On the other hand, $R_{\mathrm{G}}$ decreases with $T_{\mathrm{Q}}$ higher than $613 \mathrm{~K}$ for the $0.2 \mathrm{~mm}$ specimen but for the $0.1 \mathrm{~mm}$ specimen

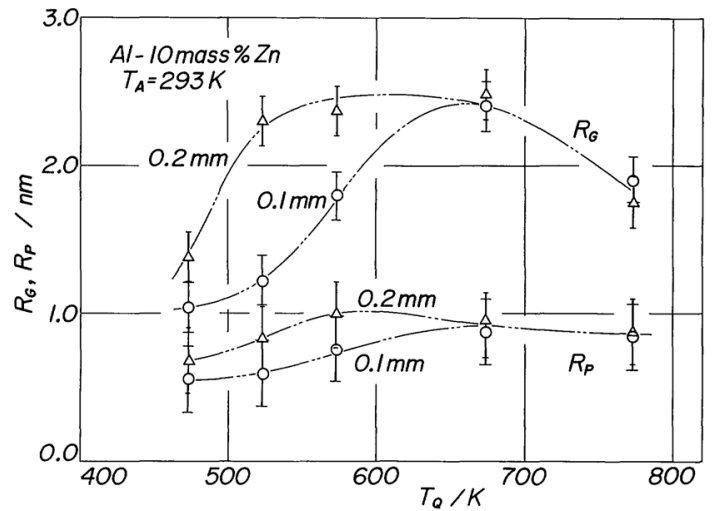

Fig. 10 Variation in $T_{\mathrm{Q}}$-dependence of $R_{\mathrm{G}}$ and $R_{\mathrm{P}}$ with thickness when $10 \%$-alloy specimens were fully aged at $293 \mathrm{~K}$.

$R_{\mathrm{G}}$ decreased with $T_{\mathrm{Q}}$ when it is higher than $673 \mathrm{~K} . R_{\mathrm{P}}$ becomes almost constant above 613 $\mathrm{K}$ and above $673 \mathrm{~K}$ for the $0.1 \mathrm{~mm}$ and $0.2 \mathrm{~mm}$ specimens respectively.

Figure 9 shows a variation of $q_{0}$, and Fig. 10 $R_{\mathrm{G}}$ and $R_{\mathrm{P}}$, with $T_{\mathrm{Q}}$ for the $10 \%$ alloy. The effects of the specimen thickness on $q_{0}, R_{\mathrm{G}}$ and $R_{\mathrm{P}}$ are similar to those observed in the $4 \%$ alloy.

\section{Discussions}

It is known that GP zones smaller than about $2.0 \mathrm{~nm}$ in radius are spherical and that they become oblate ellipsoidal as their size increases $^{(13)}$. Guinier radii found in the present experiment are often as large as $2.5 \mathrm{~nm}$ in the case of the $10 \%$ alloy. In that case the specimen was so mounted that the same area of the specimen might be irradiated. Integrated intensity $q_{0}$ of the GP zones whose shape are other than spherical can be obtained if the specimen is made up of such a large number of fine crystallites as may be regarded as "perfect powder"(14). In practice, however, grain coarsening was unavoidable under the present condition where the solution heat-treatment and annealing for strain relief had to be carried out. (It is doubtful whether usual aging behavior could be observed for a specimen which consists of crystallites fine enough to be regarded as "perfect powder" (1)). Therefore, it should be considered that the results of $q_{0}$ for 
the $10 \%$ alloy involve a little larger error. For $4 \%$ alloy, Guinier radii obtained in this experiment were all smaller than $2.0 \mathrm{~nm}$, thus GP zones in this case can be considered to be spherical.

From the results of electrical resistance and SAXS intensity of the $4 \%$ and $10 \%$ alloys, it can be recognized that, when $T_{\mathrm{Q}}$ is low, the total amount of GP zones formed in the 0.1 $\mathrm{mm}$ specimen is smaller than that in the thicker specimens beyond the experimental error. In the present study SAXS intensity of the specimen thicker than $0.2 \mathrm{~mm}$ was not measured, but it may be expected from the results of electrical resistance, that the total amount of GP zones formed in the thick specimens did not differ significantly from that formed in the $0.2 \mathrm{~mm}$ specimen.

According to the results of the hardness test $^{(1)}$, the Vickers hardness number, $H_{\mathrm{V}}$, of the surface layer, whose thickness was about 0.05 $\mathrm{mm}$, was smaller than that of the interior of the specimen. Thus the result of SAXS measurement tallies with that of the hardness test.

For both alloys, $4 \%$ and $10 \%, q_{0}$ of the 0.1 $\mathrm{mm}$ specimen is smaller than that of the 0.2 $\mathrm{mm}$ specimen when $T_{\mathrm{Q}}$ is $613 \mathrm{~K}$ or lower. When $T_{\mathrm{Q}}$ is $673 \mathrm{~K}$ or higher, $q_{0}$ depends neither on the specimen thickness nor on $T_{\mathrm{Q}}$. The latter result that the value of $q_{0}$ was independent of the thickness and $T_{\mathrm{Q}}$ when $T_{\mathrm{Q}}$ was $673 \mathrm{~K}$ or higher, may be considered to indicate that the value corresponds to that which should be obtained when the precipitation of spherical GP zones was completed. The former result seems to indicate that, in the $0.1 \mathrm{~mm}$ specimen quenching from low temperatures, the rate of precipitation became substantially zero before the spherical GP zones had been fully precipitated (when the specimen $0.1 \mathrm{~mm}$ thick of the $4 \%$ alloy was aged at $263 \mathrm{~K}$ after quenching from $613 \mathrm{~K}, q_{0}$ obtained after aging $6000 \mathrm{ks}$ did not differ from that obtained after aging $72 \mathrm{ks}$ within the experimental error).

Although several specimens were used in turn repeatedly, the values of integrated intensity (the amount of precipitation) coincided each other within the experimental error when $T_{\mathrm{Q}}$ was $673 \mathrm{~K}$ or higher, in spite of the fact

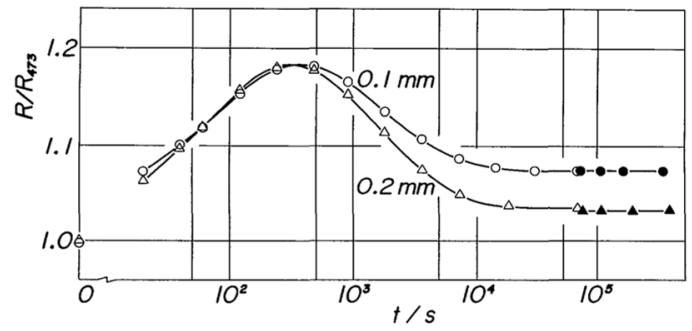

Fig. 11 Variation in the effect of lowering aging temperature with thickness when 10\%-alloy specimens were quenched from $573 \mathrm{~K}$, aged at $293 \mathrm{~K}$ and then aged further at $273 \mathrm{~K}$.

that the following procedures were repeated; homogenization at $773 \mathrm{~K}$ for $3.6 \mathrm{ks}$ in the furnace, furnace-cooling to the quenching temperature, keeping at the temperature for an hour, and then quenching and aging. This indicates that dezincification did not occur during these heat treatments.

It is considered that the driving force for precipitation must not have been zero when the rate of precipitation became substantially zero in the case of low $T_{\mathrm{Q}}$, since the value of $q_{0}$ was smaller than that in the case of high $T_{\mathrm{Q}}$. Therefore, it may be due to the decrease of vacancy concentration for the diffusion of zinc atoms that the rate became practically zero. Figure 11 shows the resistance changes, $R / R_{473}$ vs $t$, of the $10 \%$ alloy at $273 \mathrm{~K}$ after aging at $293 \mathrm{~K}$ for $66 \mathrm{ks}$. In these procedures the aging temperature was lowered when the changes at $293 \mathrm{~K}$ almost stopped and thus the driving force for precipitation was increased. A decrease in $R / R_{473}$ was observed in the curve of the $0.2 \mathrm{~mm}$ specimen, which indicated that further precipitation occurred. On the other hand, $R / R_{473}$ did not change in the $0.1 \mathrm{~mm}$ specimen. The driving force to precipitation in the $0.1 \mathrm{~mm}$ specimen just after the lowering of the aging temperature to $273 \mathrm{~K}$ must have been larger than in the $0.2 \mathrm{~mm}$ specimen, since smaller $q_{0}$ was obtained for the $0.1 \mathrm{~mm}$ specimen than the $0.2 \mathrm{~mm}$ specimen after aging at $293 \mathrm{~K}$. Therefore, the result suggests that there remained enough vacancies to promote precipitation in the $0.2 \mathrm{~mm}$ specimen but not in the $0.1 \mathrm{~mm}$ specimen after aging for $66 \mathrm{ks}$ at 293 $K$. The difference in the remaining vacancy 
concentration with thickness beyond $293 \mathrm{~K}$ aging was considered to be induced by the annihilation of vacancy at the surface, if the grain size and the dislocation density did not differ so much between the specimens (the average grain diameter in the specimen was indeed nearly equal, about $0.7 \mathrm{~mm}$ ).

It was examined whether or not the decrease in the vacancy concentration occurred mainly during quenching or during aging for a long time. For this purpose, the annihilation of vacancies at the surface during quenching and aging was estimated by solving the diffusion equations numerically. The cooling curve was approximated by three straight lines, each resembling the portion of the curve which was obtained experimentally. Effective migration energy of the vacancy in these alloys was assumed to be $0.43 \mathrm{eV}$. According to this calculation, the vacancy concentration during quenching decreased considerably in the region within several $\mu \mathrm{m}$ from the surface, but in the region beyond a depth of $10 \mu \mathrm{m}$, it remained at a value larger than $90 \%$ of that at the center of the thickness. After aging for $60 \mathrm{ks}$ at $263 \mathrm{~K}$, on the other hand, the vacancy concentration in the region within about $25 \mu \mathrm{m}$ from the surface decreased to a value less than a half of the vacancy concentration of the center. If the jump frequency of a solute atom in a certain region may be assumed to be proportional to the vacancy concentration in that region, total jumps of the solute atom during aging showed the depth dependence that corresponds to the vacancy concentration.

It may be supposed that there must be a lower-limit of jumps necessary for the precipitation of spherical GP zones to completion when an alloy of a given composition is aged at a given temperature. In the region where enough vacancies exist and then the total jumps of a solute atom during aging exceeds the limit, a constant amount of zones which corresponds to the aging temperature can be formed. On the other hand, in the region where total jumps do not amount to the limit, aging stops before the precipitation has ended. In each region, the solute concentration in the matrix varies during aging and then the supersaturation of solute concentration for the
GP zone formation varies accordingly. It is considered that the tendency for solute atoms in the matrix to be taken into a GP zone varies with the solute supersaturation in the matrix. The evaluation of this tendency and the lowerlimit of jumps is difficult, as is a quantitative calculation of the dependence of the amount of precipitation on the depth. Nevertheless, because the amount of precipitation is considered to be a monotonously increasing function of the total jumps, it is understood qualitatively that the amount of precipitation is small in the region where the vacancy concentration decreases rapidly. Accordingly the total number of jumps is small. This effect will increase with decreasing thickness: The calculated ratio of average jumps of a solute atom in the $0.1 \mathrm{~mm}$ specimen to that in the 0.2 $\mathrm{mm}$ specimen is about $3 / 4$ in $60 \mathrm{ks}$ aging and is less than $1 / 2$ in $300 \mathrm{ks}$.

Figure 8 shows that $R_{\mathrm{G}}$ is largest when $T_{\mathrm{Q}}=613 \mathrm{~K}$ for the $0.2 \mathrm{~mm}$ specimens of $4 \%$ alloy. It was suggested ${ }^{(15)}$ that the decrease of $R_{\mathrm{G}}$ with $T_{\mathrm{Q}}$ was due to the secondary defects such as dislocation loops formed when $T_{\mathrm{Q}}$ was high. The secondary defects act as sinks for vacancies. Accordingly a lower vacancy concentration may suppress precipitation of GP zones. In the present study a decrease in the total amount of GP zones has not been recognized in the case of high $T_{\mathrm{Q}}$ up to $773 \mathrm{~K}$. The quenching temperature at which $R_{\mathrm{G}}$ began to decrease with decreasing temperature is higher for the $0.1 \mathrm{~mm}$ specimen than that for the $0.2 \mathrm{~mm}$ specimen; they are coincident with the quenching temperatures at which $q_{0}$ began to decrease from the constant value, respectively. It is also seen in the case of $R_{\mathrm{P}}$. This fact indicates that, as in the case of $q_{0}$, the growth of GP zones was also suppressed by the decrease of vacancies.

\section{Conclusion}

Effect of the specimen thickness on the aging of $\mathrm{Al}-4$ and 10 mass $\% \mathrm{Zn}$ alloys was studied by measurements of electrical resistance and the intensity of small-angle X-ray scattering (SAXS). The results are as follows:

(1) When the quenching temperature $\left(T_{\mathrm{Q}}\right)$ 
was high, the value of $R_{\mathrm{E}} / R_{473}$ attained at the stage of aging where the resistance virtually ceased to change was not influenced by the specimen thickness. In the case of low $T_{\mathrm{Q}}, R_{\mathrm{E}} /$ $R_{473}$ was higher for the thin specimen, caused by impoverishment of vacancies.

(2) The initial rate of resistance change during aging was independent of the specimen thickness.

(3) The integrated intensity of SAXS depended on the thickness and on $T_{\mathrm{Q}}$ when $T_{\mathrm{Q}} \leqq 613 \mathrm{~K}$; it decreased with a decreasing thickness and with a decreasing $T_{\mathrm{Q}}$.

(4) The integrated intensity did not depend upon the thickness or $T_{\mathrm{Q}}$ when $T_{\mathrm{Q}} \geqq 673 \mathrm{~K}$.

(5) Both Guinier radius and Porod radius for the specimen of $0.1 \mathrm{~mm}$ thickness were smaller than those for the one of $0.2 \mathrm{~mm}$ thickness when $T_{\mathrm{Q}}$ was low, but they became independent of the thickness when $T_{\mathrm{Q}} \geqq 673 \mathrm{~K}$.

(6) The quenching temperature at which the Guinier radius was maximum was higher for the $0.1 \mathrm{~mm}$ thick specimen than for the 0.2 $\mathrm{mm}$ thick one. The quenching temperature at which the Guinier radius and the Porod radius began to decrease with decreasing temperature was coincident with the quenching temperature at which the integrated intensity began to decrease from the constant value.

(7) The fact that the states attained after ag- ing differ depending on the specimen thickness is considered to be due to insufficient aging near the surface where the vacancy concentration is lowered by the annihilation of vacancies at the surface during aging.

\section{REFERENCES}

(1) M. Ohta, H. Yamada, T. Kanadani, A. Sakakibara and M. Yamada: Light Metals, 33 (1983), 212.

(2) M. Ohta and F. Hashimoto: J. Japan Inst. Metals, 36 (1972), 321.

(3) M. Ohta, T. Kanadani and A. Sakakibara: J. Japan Inst. Metals, 47 (1983), 375.

(4) A. Csanády, V. Stefaniay and D. L. Beke: Mat. Sci. Eng., 38 (1979), 55.

(5) M. Yamada, M. Ohta and A. Sakakibara: J. Japan Inst. Metals, 46 (1982), 459.

(6) M. Yamada, A. Sakakibara and M. Ohta: Mem. Sch. Eng. Okayama Univ., 20 (1985), 35.

(7) International Tables for X-ray Crystallography Vol. $I V$, Kynoch Press, Birmingham, England (1974).

(8) D. T. Cromer and D. Liberman: J. Chem. Phys., 53 (1970), 1891.

(9) D. T. Cromer and J. B. Mann: J. Chem. Phys., 47 (1967), 1892.

(10) D. T. Cromer: J. Chem. Phys., 50 (1969), 4857.

(11) M. Ohta, T. Kanadani, M. Yamada and A. Sakakibara: Light Metals, 29 (1979), 315.

(12) R. Roth: J. Appl. Cryst., 10 (1977), 172.

(13) R. Ramlau and H. Loeffler: Phys. Status Solidi (a), 68 (1981), 531.

(14) A. Guinier: X-ray Diffraction, W. H. Freeman and Company, San Francisco (1963), p. 49.

(15) T. Sato, Y. Kojima and T. Takahashi: Light Metals, 28 (1978), 506. 